\title{
Assessment of Rutting Resistance and Healing for Stone Matrix Asphalt Concrete (SMAC)
}

\author{
Saad Issa Sarsam, Shahed Mahmood Khalil \\ Department of Civil Engineering, College of Engineering, University of Baghdad, Baghdad, \\ Iraq \\ E-mail: saadisasarsam@coeng.uobaghdad.edu.iq
}

\begin{abstract}
Stone Matrix Asphalt Concrete (SMAC) is known as tough, stable, rut-resistant mixture. In this investigation, SMAC was prepared in the laboratory using gap graded aggregates, asphalt cement, mineral filler and coal fly ash as stabilizing agent. Specimens were prepared using static compaction to the target density based on asphalt content for each case. The prepared Specimens were subjected to the 1200 repeated compressive stresses at $25^{\circ} \mathrm{C}$ under various stress levels using the pneumatic repeated load system PRLS. Specimens were subjected to microcrack healing process by external heating for 120 minutes at $60^{\circ} \mathrm{C}$, then it practices another cycle of repeated compressive stresses. The resilient modulus, permanent deformation, and rutting resistance under three levels of stress have been assessed. It was concluded that the resilient modulus Mr increases by $(66,50$ and 31) \%, (36, 50 and 31$) \%$ and $(62,37$ and 69$) \%$, while the permanent deformation decreases by $(25,11.4$ and 25$) \%,(19,31.6$ and 14.5$) \%$ and $(14,9$ and 8.3$) \%$ after implementation of fly ash at (OAC-0.5, OAC and OAC+0.5) \% binder content under $(0.068,0.138$ and 0.206$) \mathrm{MPa}$ of repeated compressive stress respectively. The resilient modulus increased by $(17.6,15.3,10.5) \%,(42.8,51,37.5) \%$ and $(18.7,25,23.6) \%$ and the permanent deformation decline by $(3.52,31.66,6.25) \%$ under repeated compressive stresses of $(0.068,0.138,0.206) \mathrm{MPa}$ at $\left(25^{\circ} \mathrm{C}\right)$ after healing for mix with $(4.6,5.1,5.6) \%$ asphalt content respectively when compared with mixtures before healing. Keywords: Stone matrix asphalt; Deformation; Rutting; Resilient Modulus; Healing.
\end{abstract}

\section{Introduction}

The SMA design concept relies on stone-on-stone contact to provide strength and a rich mortar binder to provide durability. These objectives are usually achieved with a gap-graded aggregate coupled with fiber and/or polymermodified, high asphalt content matrix, [1]. Figure 1 exhibit the stone-on stone contact and the active and inactive particles in SMA.
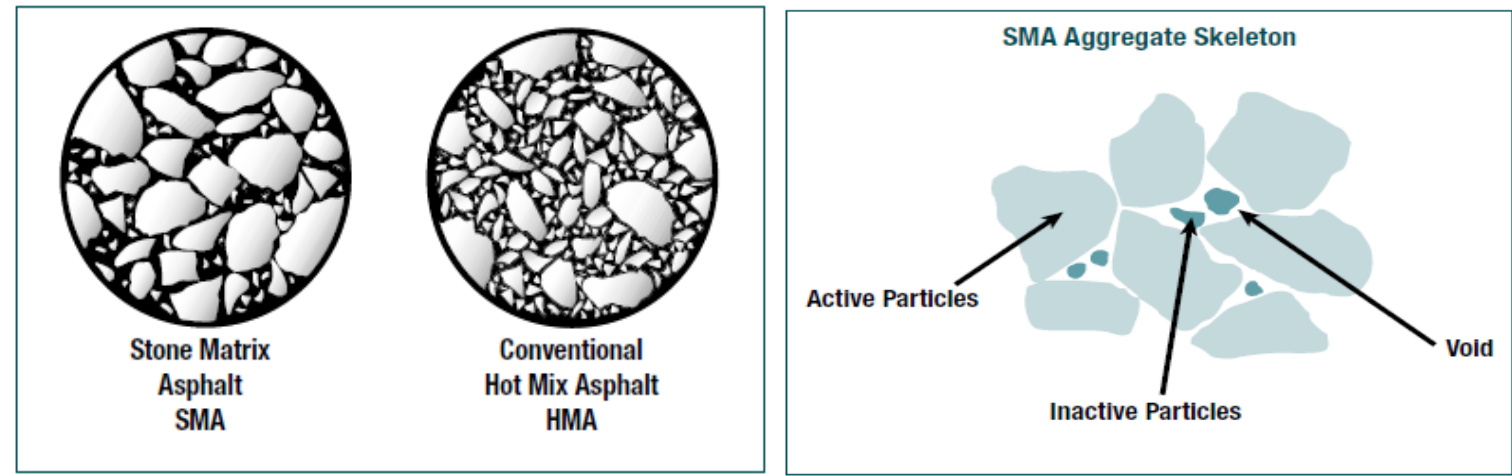

Figure 1. Aggregate contact in SMA, NAPA, [1]

Ghasemia and Marandi, [2] evaluated the advantages of adding styrene butadiene styrene (SBS) polymer to the base bitumen with the penetration grade of $60 / 70$ and to modify stone matrix asphalt (SMA) in flexible pavement. Different combinations were provided by mixing different amounts of SBS with base bitumen. Then, asphalt mixture performance tests including indirect tensile strength and resilient modulus were performed on the modified and control asphalt samples. It was concluded that the mixture test results demonstrated $34 \%$ higher tensile strength in the temperature range of $25^{\circ} \mathrm{C}, 26 \%$ lower moisture susceptibility, $167 \%$ higher toughness index, higher compression strength in different conditions and $127 \%$ increase in resilient modulus values at $25^{\circ} \mathrm{C}$. As reported by Cooley and Brown, [3], Stone matrix asphalt (SMA) has been used and have had either a (12.5 or 19.0) mm nominal maximum aggregate size (NMAS). However, the existence of a fine SMA mix could be beneficial because 
it can be placed in thinner lifts, could be used as part of a preventative maintenance program, and should be more workable. It was concluded that SMA could be successfully designed to have stone-on-stone contact.

Fine SMA mixes were rut resistant and thus should be more durable. Permanent deformation test on SMA was conducted by Awanti, [4] using immersion wheel tracking test. The wheel tracking apparatus measures combined effects of rutting and moisture damage by rolling a rubber wheel across the surface of an asphalt slab. It was concluded that SMA shows $42 \%$ higher rut resistance when compared to control mixture. Babagoli et al., [5] studied the impact of additives on resilient modulus of SMA. The results indicate that in general, the mixtures containing additives have higher resilient modulus values than mixtures containing no additives. The modified binders are stiffer and have a better tensile strength. Thus, the improvement in resilient modulus of mixtures containing additives is attributed to the stiffer-modified binders. The dynamic stiffness or resilient modulus is a measure of the load-spreading ability of the bituminous layers as stated by Mashaan et al., [6]; it controls the levels of the traffic induced tensile strains at the underside of the lowest bituminous bound layer which are responsible for fatigue cracking, as well as the stresses and strains induced in the subgrade that can lead to plastic deformations.

The test was conducted on SMA specimens by applying compression loads with a prescribed sinusoidal waveform. It was concluded that the stiffness modulus of reinforced SMA samples containing various contents of crumb rubber modifier (CRM) is significantly high in comparison with that of nonreinforced samples. The stiffness modulus of reinforced samples is in fact less severely affected by the increased temperature compared to the nonreinforced samples. Chiu and Lu, [7] investigated the feasibility of using asphalt rubber (AR), produced by blending ground tire rubber (GTR) with an asphalt, as a binder for stone matrix asphalt (SMA). Two different sizes of GTR produced in Taiwan were used. The potential performance of AR-SMA mixtures was also evaluated. It was noted that SMA mixtures meeting typical volumetric requirements for SMA could be produced using an asphalt rubber containing $20 \%$ of a fine GTR with a maximum size of $0.6 \mathrm{~mm}$. No fiber was needed to prevent drain-down when this asphalt rubber was used. It was concluded that rutting resistance of AR-SMA mixtures was better than that of the conventional SMA mixtures. Two aggregate gradations, with nominal maximum aggregate sizes (NMAS) 16 and $13 \mathrm{~mm}$ were adopted to prepare SMA mixtures and their laboratory performances were compared by Sarang et al., [8]. Polymer-modified bitumen (PMB) was used as the binder material and no stabilizing additive was used. Conventional cylindrical specimens were prepared in super pave gyratory compactor. Tensile strength was checked for cylindrical specimens prepared at optimum bitumen content, whereas specially prepared slab specimens were used to check the rutting resistance of SMA mixtures. It was concluded that SMA 1 mixture was better resistant to rutting, and in wheel-tracking test, deformations were $0.4-0.7 \mathrm{~mm}$ less than SMA 2 slab for all wheel passes. After 10,000 passes rut depth was $4.1 \mathrm{~mm}$ for SMA 1, compared to $4.8 \mathrm{~mm}$ in the case of SMA 2 slab. Sarsam and Khalil, [9] studied the behavior of SMA under repeated tensile stress and moisture damage, It was concluded that Resilient modulus Mr of SMA mixture with stabilizing agent (coal fly ash) is higher than the values attained for SMA mixture without fly ash by $30 \%$ in general, while Mr decalin by $50 \%$ after moisture damage.

The aim of this investigation is the assessment of Rutting Resistance for Stone Matrix Asphalt Concrete (SMAC) under repeated compressive stresses. The influence of asphalt content and fly ash on resilient modulus and permanent deformation before and after crack healing will be investigated.

\section{Materials and methods}

\subsection{Asphalt cement}

Asphalt cement was obtained from Dora refinery; the physical properties are shown in Table 1.

Table1. Physical Properties of Asphalt Cement

\begin{tabular}{llll}
\hline Test procedure as per ASTM, [10] & Result & Unit & SCRB, [11] Specification \\
\hline Penetration $\left(25^{\circ} \mathrm{C}, 100 \mathrm{~g}, 5 \mathrm{sec}\right)$ ASTM D 5 & 43 & $1 / 10 \mathrm{~mm}$ & $40-50$ \\
Ductility $\left(25^{\circ} \mathrm{C}, 5 \mathrm{~cm} / \mathrm{min}\right)$. ASTM D 113 & 156 & $\mathrm{Cm}$ & $\geq 100$ \\
Softening point (ring \& ball). ASTM D 36 & 49 & ${ }^{\circ} \mathrm{C}$ & $50-60$ \\
After Thin-Film Oven Test ASTM D-1754 & & & \\
Retained penetration of original, \% ASTM D 946 & 31 & $1 / 10 \mathrm{~mm}$ & $<55$ \\
Ductility at $25^{\circ} \mathrm{C}, 5 \mathrm{~cm} / \mathrm{min},(\mathrm{cm})$ ASTM D-113 & 147 & $\mathrm{Cm}$ & $>25$ \\
Loss in weight $\left(163^{\circ} \mathrm{C}, 50 \mathrm{~g}, 5 \mathrm{~h}\right) \%$ ASTM D-1754 & 0.175 & $\%$ & - \\
\hline
\end{tabular}

\subsection{Coarse and fine aggregates}

Coarse and fine aggregates were obtained from Al-Nibaee quarry, Table 2 shows the physical properties of aggregates. 
Table 2. Physical Properties of Al-Nibaee Coarse and fine Aggregates

\begin{tabular}{lll}
\hline Property as per ASTM, [10] & Course Aggregate & Fine Aggregate \\
\hline Bulk Specific Gravity (ASTM C 127 and C 128) & 2.610 & 2.631 \\
Apparent Specific Gravity (ASTM C 127 and C 128) & 2.641 & 2.6802 \\
Percent Water Absorption (ASTM C 127 and C 128) & 0.423 & 0.542 \\
Percent Wear (Los-Angeles Abrasion) (ASTM C 131) & 20.10 & - \\
\hline
\end{tabular}

\subsection{Mineral filler}

The mineral filler passes sieve No.200 $(0.075 \mathrm{~mm})$. The filler used in this work is limestone dust and was obtained from Karbala governorate. The physical properties of the filler are presented in Table 3.

Table 3. Physical Properties of Filler (Limestone dust).

\begin{tabular}{ll}
\hline Property & Value \\
\hline Bulk specific gravity & 2.617 \\
$\%$ Passing Sieve No.200 & 94 \\
\hline
\end{tabular}

\subsection{Stabilizing additive}

Coal Fly ash was used in this work. Fly ash was added at $1 \%$ by weight of aggregate, the chemical properties for fly ash are listed in Table 4 . Table 5 shows physical properties of Fly ash.

Table 4. Chemical Properties of Fly Ash.

\begin{tabular}{llll}
\hline Property & Percent \% & \multicolumn{2}{l}{ ASTM, [10] C 618 Specifications } \\
\cline { 3 - 4 } & & Class F & Class C \\
\hline $\mathrm{SiO} 3$ & 54.70 & $\mathrm{SiO} 3+\mathrm{Al} 2 \mathrm{O} 3+\mathrm{Fe} 2 \mathrm{O} 3$ & $\mathrm{SiO} 3+\mathrm{Al} 2 \mathrm{O} 3+\mathrm{Fe} 2 \mathrm{O} 3$ \\
$\mathrm{~A} 2 \mathrm{O} 3$ & 31.91 & $\geq 70 \%$ & $\geq 50 \%$ \\
$\mathrm{Fe} 2 \mathrm{O} 3$ & 8.79 & & \\
$\mathrm{SO} 3$ & 0.06 & $\leq 5 \%$ & $\leq 5 \%$ \\
$\mathrm{CaO}$ & 1.50 & --- & --- \\
\hline
\end{tabular}

Table 5. Physical Properties of Fly ash

\begin{tabular}{ll}
\hline Property & Value \\
\hline specific gravity & 2.0 \\
Passing Sieve No. $200 \%$ & $99 \%$ \\
Specific surface area $\left(\mathrm{m}^{2} / \mathrm{kg}\right)$ & 650 \\
\hline
\end{tabular}

\subsection{Selection of asphalt concrete combined gradation}

The selected gradation in this work follows the Gap gradation suggested by many researchers, Brown et al., [12]; Asi, [13]; Myers, [14]; Nejad et al., [15]; and Bernard, [16]. Figure 2 demonstrates the gradation adopted with $12.5(\mathrm{~mm})$ nominal maximum size of aggregates.

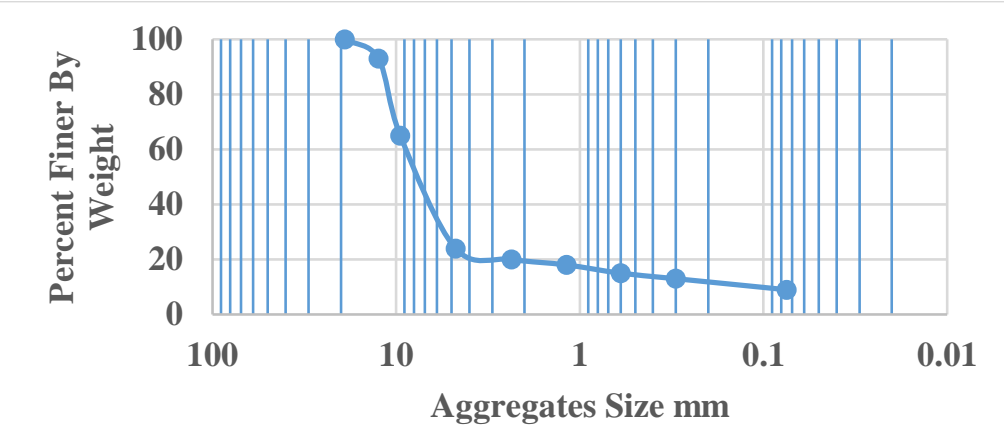

Figure 2. Combined Gradation Adopted

\subsection{Preparation of SMAC mixture}

The aggregate was dried to a constant weight at $110^{\circ} \mathrm{C}$, then sieved to different sizes, and stored. Coarse and fine aggregates were combined with mineral filler to meet the specified gradation shown in Figure 2 . The combined 
aggregate mixture was heated to a temperature of $150^{\circ} \mathrm{C}$ before mixing with asphalt cement, then added fly ash to the aggregate and mixing together. The asphalt cement was heated to the same temperature of $150{ }^{\circ} \mathrm{C}$, then it was added to the heated aggregate to achieve the desired amount and mixed thoroughly using mechanical mixer for two minutes until all aggregate particles were coated with thin film of asphalt cement. Cylindrical specimens of $102 \mathrm{~mm}$ diameter and $102 \mathrm{~mm}$ height were prepared using static compaction to the target density based on asphalt content for each case. The optimum asphalt content was determined as per Marshal method to be (5.1 and 5.3) \% by weight of aggregates for mixture without and with stabilizing agent (coal fly ash) respectively. Similar procedure was reported by Sarsam and Khalil, [9].

\subsection{Repeated compressive stresses test}

The prepared Specimens were subjected to the repeated compressive strength test at $25^{\circ} \mathrm{C}$ under various stress levels using the pneumatic repeated load system PRLS. The load assembly applies compressive stresses on the specimen in the form of rectangular wave with constant loading frequency of (60) cycles per minutes. A heavier sine pulse of (0.1) sec load duration and (0.9) sec rest period was applied over the test duration. Before the test, dial gage of the deformation reading was set to zero and the pressure actuator was adjusted to the specific stress level of $(0.068,0.138,0.206) \mathrm{MPa}$. A digital video camera was fixed on the top surface of the (PRLS) to capture dial gage reading. The average deformation of triplicate specimens was calculated and considered for obtaining the resilient modulus and permanent deformation. Additional asphalt concrete specimens have been prepared using asphalt cement of $0.5 \%$ above and below the optimum asphalt content. Similar procedure was reported by Sarsam and Jasim, [17].

\subsection{Microcrack healing process}

The repeated compressive stress test was continued for 1200 load repetitions, upon completion of test, the recording was terminated. Specimens were withdrawn from the PRLS and stored in an oven for 120 minutes at $60^{\circ} \mathrm{C}$ to allow the crack healing process by external heating. Specimens were returned to the PRLS chamber, conditioned for 60 minutes at $40 \pm 1{ }^{\circ} \mathrm{C}$ and subjected to another 1200 load repetitions, the deformation was monitored by digital camera throughout the test. The average of three specimens was calculated and considered for analysis as recommended by Sarsam, [18]. Figure 3 demonstrates the repeated compressive stress test assembly and part of the prepared specimens.
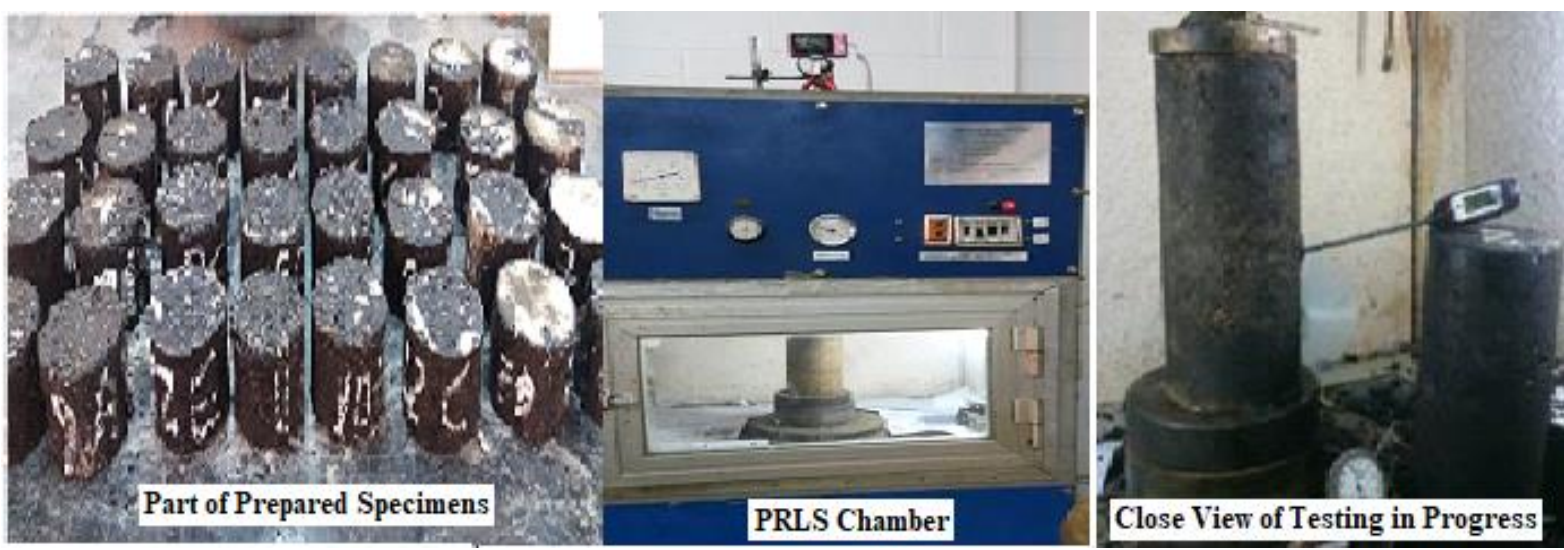

Figure 3. The Repeated Compressive Stress Testing Apparatus and SMAC Specimens

\section{Results and discussions}

\subsection{Effect of asphalt content and fly ash on resilient modulus of SMAC}

Based on the test results, the asphalt content has positive effect on the elastic response of asphalt material. The variation of the resilient modulus $\mathrm{Mr}$ as related with asphalt content is presents in Figure 4. Test results of Stone Matrix Asphalt Mixture without implementation of additives at $0.068 \mathrm{MPa}$ stress level show that the Mr decreased by (28.57 and 24.9) \% when the asphalt content increased and decreased by $0.5 \%$ from OAC respectively. The test results at $0.138 \mathrm{MPa}$ show that the Mr decreased by (18.18 and 10) \% when the asphalt content increased and decreased by $0.5 \%$ from OAC respectively. The test results of Stone Matrix Asphalt Mixture at 0.206 MPa show that the Mr decreased by (36.36 and 26.31) \% when the asphalt content increased and decreased by $0.5 \%$ from OAC respectively. The higher Mr could be achieved at $0.068 \mathrm{MPa}$ stress level and at OAC, this may be attributed to the requirement of asphalt which must be enough to bind the aggregates under the low traffic loading. Similar behavior could be noticed at moderate and high traffic loading as the higher level of stress will possess additional 
compressive stresses. On the other and, when coal fly ash was introduced as stabilizing agent, the resilient modulus exhibits higher values as compared to the mixtures without fly ash regardless of the asphalt content. The $\mathrm{Mr}$ increases by $(66,50$ and 31) \%, (36, 50 and 31) \% and (62, 37 and 69) \% after implementation of fly ash at (OAC0.5 , OAC and $\mathrm{OAC}+0.5) \%$ binder content under $(0.068,0.138$ and 0.206$) \mathrm{MPa}$ of repeated compressive stress respectively. This may be attributed to the fact that implication of fly ash will block more voids and increase the viscosity of the binder which in turn increase the flexibility and resilience of the mixture. Such findings agree well with the work reported by NAPA, [19] and Tashmana and Pearson, [20].

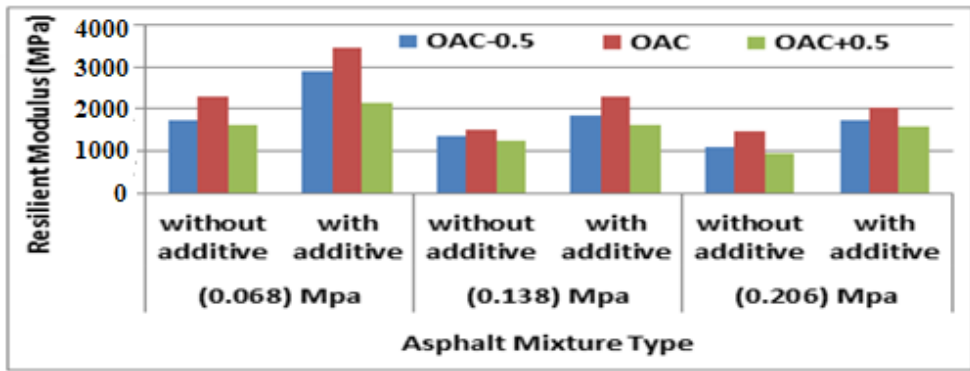

Figure 4. Influence of Asphalt Content and Additive on Resilient Modulus of SMAC

\subsection{Effect of asphalt content and fly ash on permanent deformation of SMAC}

As demonstrated in Figure 5, mixtures with optimum asphalt content exhibits lower deformation potential as compared with other asphalt percentages regardless of the implementation of fly ash. This may be attributed to the enough cohesion provided by the OAC. When the asphalt content increases by $0.5 \%$ above OAC, the binder film thickness increases which allow the lubrication and sliding of particles under load repetitions, while when the binder content is $0.5 \%$ below the OAC, it seems to be insufficient to provide a proper cohesion and will practice more permanent deformation under repeated loading. For mixtures without stabilizing additives (fly ash), when SMAC undergo low stress level of $0.068 \mathrm{MPa}$, the permanent deformation was increased by (147.6 and 23.8$) \%$ when the asphalt content increased and decreased by $0.5 \%$ from OAC respectively, this behavior of materials agrees with the results of Ahmadinia, [21].

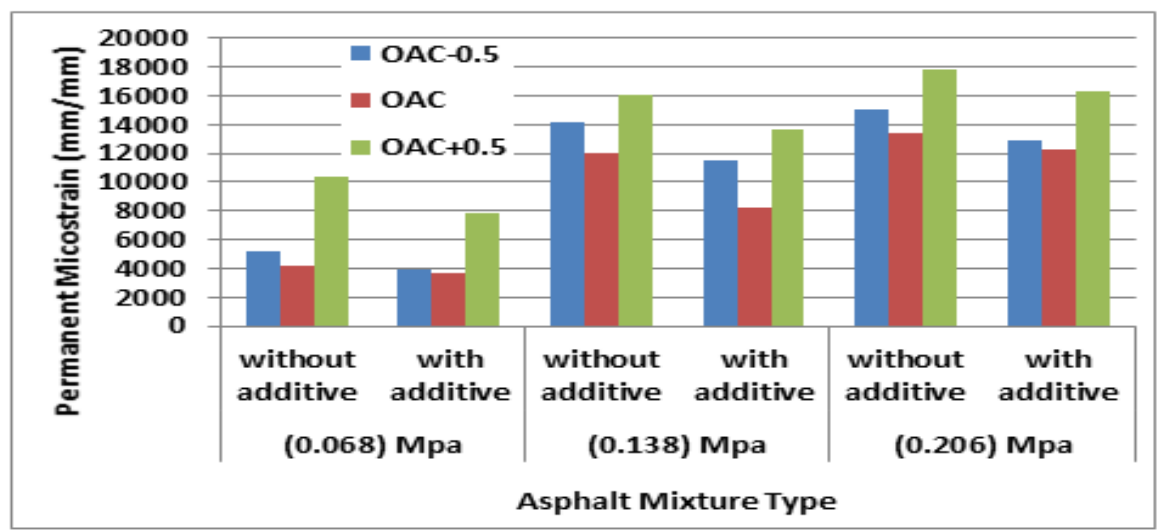

Figure 5. Influence of Asphalt Content and Additive on Permanent Microstrain of SMAC

When Stone Matrix Asphalt Mixture undergo moderate stress level of $0.138 \mathrm{MPa}$, the permanent deformation was increased by (33.33 and 18.33) \% when the asphalt content increased and decreased by $0.5 \%$ from OAC respectively. When Stone Matrix Asphalt Mixture practices high stress level of $0.206 \mathrm{MPa}$, the permanent deformation was increased by (32.83 and 11.94) \% when the asphalt content increased and decreased by $0.5 \%$ from $\mathrm{OAC}$ respectively. It can be noted that the development of permanent deformation is strongly dependent on the stress level, the permanent deformation increases with increasing stress. Similar findings were reported by Sarsam and Husain, [22]. When the stabilizing agent (fly ash) was implemented in the SMAC mixture, significant reduction in permanent deformation could be observed. This could be attributed to the fact that more voids are blocked by fly ash which increases the stiffness of the mixture and provide more resistance to deformation. The permanent deformation decreases by $(25,11.4$ and 25) \%, $(19,31.6$ and 14.5$) \%$ and $(14,9$ and 8.3$) \%$ after implementation of fly ash at (OAC-0.5, OAC and OAC+0.5) \% binder content under $(0.068,0.138$ and 0.206$)$ $\mathrm{MPa}$ of repeated compressive stress respectively. 


\subsection{Effect of asphalt content and fly ash on permanent deformation parameters of SMAC}

Figure 6 exhibit the influence of asphalt content and stress levels on permanent deformation parameters (intercept and slope) for SMAC without stabilizing additive. It was observed that the value of the intercept and the slope increase for the different mixtures when increasing the level of stress. The intercept represents the permanent microstrain after the first load repetition. Lower value of intercept indicates better resistance of the mixture to permanent deformation. On the other hand, the slope represents the rate of deformation in the mixture under load repetitions. Lower slope indicates better resistance of the mixture to the propagation of permanent deformation.

Test results of Stone Matrix Asphalt Mixture under 0.068 MPa show that the intercept was increased by (177.49 and 11.36) \% when the asphalt content increased and decreased by $0.5 \%$ from OAC respectively. Test results of Stone Matrix Asphalt Mixture under 0.138 MPa show that the intercept was increased by (100.1 and 42.99) \% when the asphalt content increased and decreased by $0.5 \%$ from OAC respectively. SMAC under $0.206 \mathrm{MPa}$ stress exhibit that the intercept was increased by $(70$ and 71$) \%$ when the asphalt content increased and decreased by $0.5 \%$ from OAC respectively. The variation in slope value is not significant for different mixtures and different level of stresses.

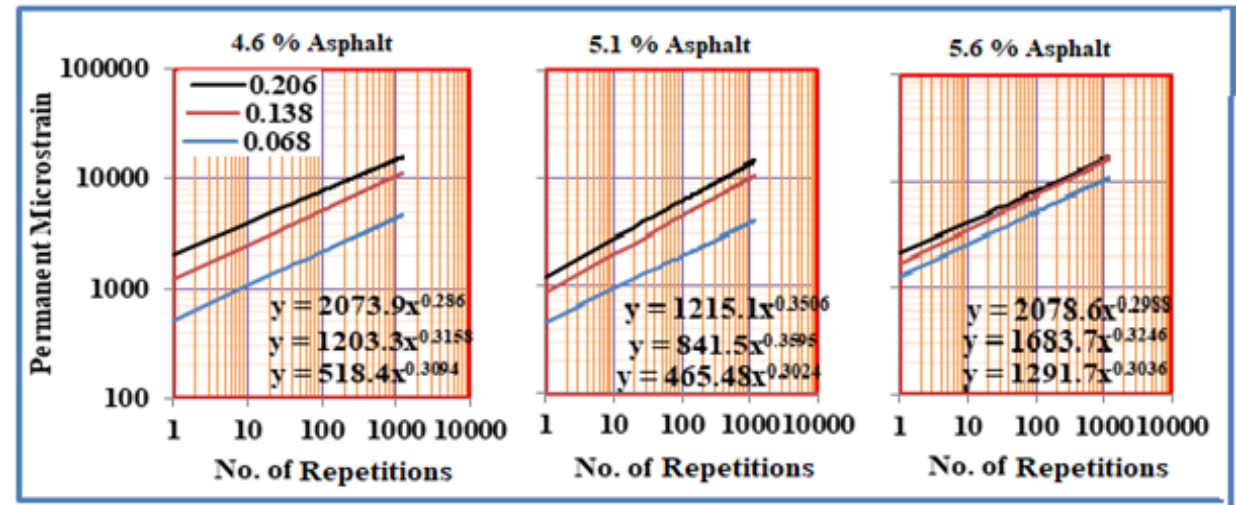

Figure 6. Permanent Deformation of SMAC without Stabilizer

Figure 7 demonstrate the influence of asphalt content and stress levels on permanent deformation parameters (intercept and slope) for SMAC after inclusion of stabilizing additive. Test results of Stone Matrix Asphalt Mixture under $0.068 \mathrm{MPa}$ show that the intercept was increased by (45.3 and 332) \% when the asphalt content increased and decreased by $0.5 \%$ from OAC respectively. Test results of Stone Matrix Asphalt Mixture under $0.138 \mathrm{MPa}$ show that the intercept was increased by (6.9 and 109) \% when the asphalt content increased and decreased by $0.5 \%$ from OAC respectively. SMAC under $0.206 \mathrm{MPa}$ stress exhibit that the intercept was increased by $(0.8$ and 5.2) $\%$ when the asphalt content increased and decreased by $0.5 \%$ from OAC respectively. The variation in slope value is not significant for different mixtures and different level of stresses. The impact of using fly ash on deformation can be detected by the reduction of permanent microstrain (intercept) by $(69.6,43.2,0.5) \%$ after inclusion of fly ash at optimum asphalt content under $(0.068,0.138$ and 0.206$)$ MPa stress level respectively. Such findings are in aggrement with the work reported by Qiu and Lum, [23].

\subsection{Effect of crack healing on permanent deformation}

Figure 8 demonstrates the influence of healing cycle process after (1200) load repetitions of compressive stresses $(0.068,0.138,0.206) \mathrm{MPa}$ on permanent deformation at $25{ }^{\circ} \mathrm{C}$. It can be noted that the permanent microstrain after the healing cycle decline. The rate of decreases of permanent deformation for mixtures without fly ash with $4.6 \%$ asphalt content was $(26.9,14.3,5.7) \%$ under $(0.068,0.138,0.206) \mathrm{MPa}$ respectively when compared with deformation before (healing cycle). For mix with $5.1 \%$ asphalt content, the rate of decreases was $(3.5,31.6,6.2) \%$ for stresses of $(0.068,0.138,0.206)$ MPa respectively when compared with deformation before (healing cycle). While for mixes with $5.6 \%$ asphalt content, the rate of decreases was $(4.0,5.9,5.0) \%$ for stresses of $(0.068,0.138,0.206) \mathrm{MPa}$ respectively when compared with deformation before (healing cycle).

On the other hand, when fly ash was implemented as a stabilizing agent, further reduction of permanent deformation could be detected after healing process. Such behavior may be attributed to the stiffening and oxidation of SMAC after external heating which increases the viscosity of the binder and in turn, increases the cohesion between aggregate particles and adhesion between binder and aggregate. Mixtures with optimum asphalt content exhibits the lowest permanent microstrain among other binder percentages. Similar behavior could be detected at Sarsam, [18]. 


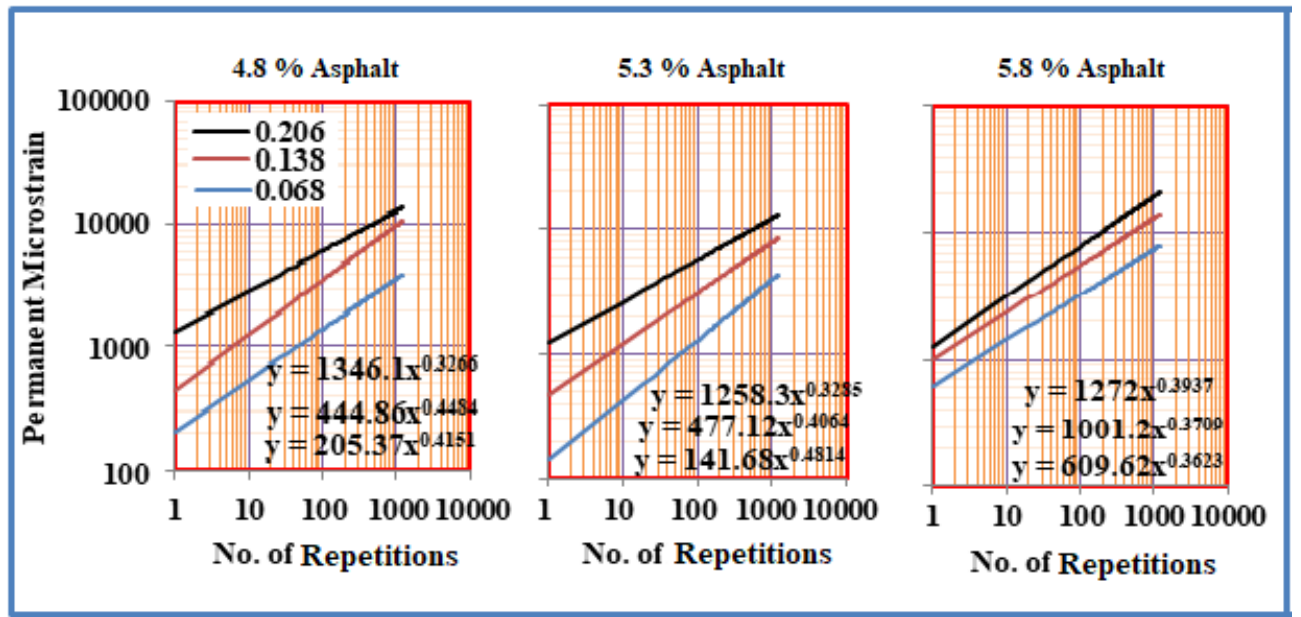

Figure 7. Permanent Deformation of SMAC with Stabilizer

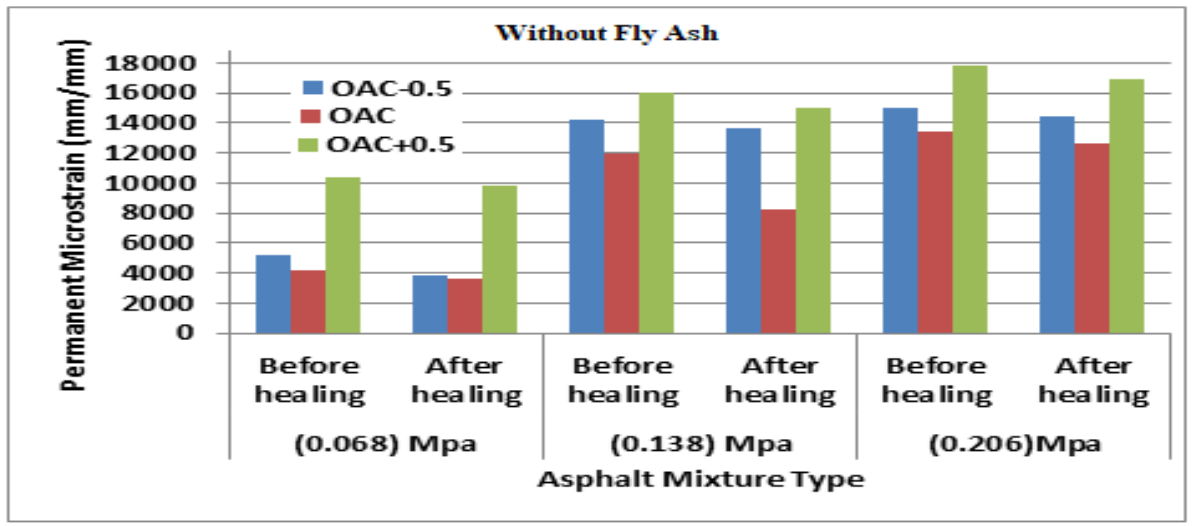

Figure 8. Influence of Healing Cycle on Permanent Deformation for Mixes (Without Fly Ash)

As demonstrated in Figure 9, it can be noted that the permanent microstrain after the healing cycle decline. The rate of decreases of permanent deformation for mixtures with fly ash at $4.6 \%$ asphalt content was $(9.7,2.6$, and $3.8) \%$ under $(0.068,0.138,0.206) \mathrm{MPa}$ respectively when compared with deformation before (healing cycle). For mix with $5.1 \%$ asphalt content, the rate of decreases was $(12.9,8.5$, and 6.5$) \%$ for stresses of $(0.068,0.138,0.206)$ $\mathrm{MPa}$ respectively when compared with deformation before (healing cycle). While for mixes with $5.6 \%$ asphalt content, the rate of decreases was $(6.6,16.5$, and 6.7) \% for stresses of $(0.068,0.138,0.206) \mathrm{MPa}$ respectively when compared with deformation before (healing cycle). The impact of fly ash was to fill more voids and reserve the coating of binder through its high specific surface area.

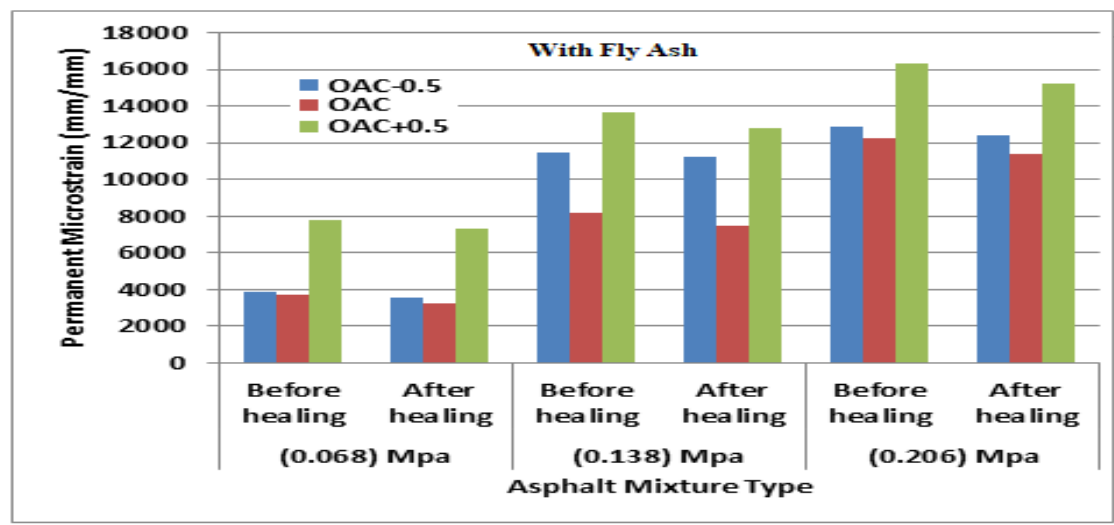

Figure 9. Influence of Healing Cycle on Permanent Deformation for Mixes (With Fly Ash)

\subsection{Effect of crack healing on resilient modulus under compressive stress}


Figure 10 exhibit demonstrations of the influence of healing cycle process under different levels of repeated compressive stress $(0.068,0.138,0.206) \mathrm{MPa}$ on resilient modulus for mixtures without fly ash. It can be noted that the resilient modulus after the healing cycle generally increased. The resilient modulus increased by (17.6, 15.4 , and 10.5) \% , (42.8, 51.0, and 37.5) \% and (18.7, 2, and 23.6) \% under three level of compressive stresses $(0.068,0.138,0.206) \mathrm{MPa}$ at $\left(25^{\circ} \mathrm{C}\right)$ after healing cycle for SMAC mixtures with $(4.6,5.1,5.6) \%$ asphalt content respectively when compared with resilient modulus before (healing cycle). This may be related to the gained flexibility due to microcrack healing process. It can be noted that the highest $\mathrm{Mr}$ values could be observed for mixtures of optimum binder content.

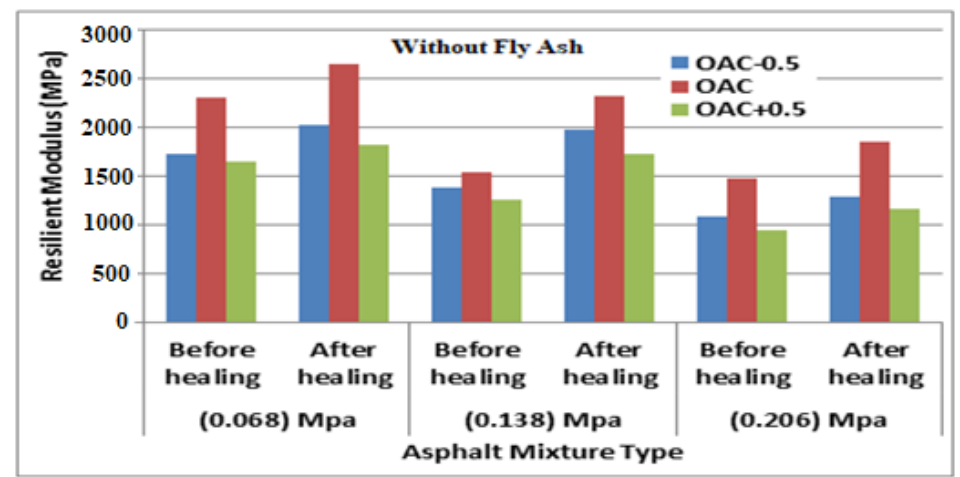

Figure 10. Influence of Healing on Mr For Mixes (Without Fly Ash)

Fig. 11 exhibit the influence of healing cycle process under different levels of repeated compressive stress $(0.068,0.138,0.206) \mathrm{MPa}$ on resilient modulus for mixtures with fly ash. It can be noted that the resilient modulus after the healing cycle generally increased and specifically at optimum binder content as compared to mixtures with other binder percentages. The resilient modulus increased by $(19.8,15.5$ and 17.7) \%, (11.3, 43.3 and 18.8) \% and $(33.4,19.5$ and 15.7$) \%$ under three level of compressive stresses $(0.068,0.138,0.206) \mathrm{MPa}$ at $\left(25{ }^{\circ} \mathrm{C}\right)$ after healing cycle for SMAC mixtures with $(4.6,5.1,5.6) \%$ asphalt content respectively when compared with resilient modulus before (healing cycle).

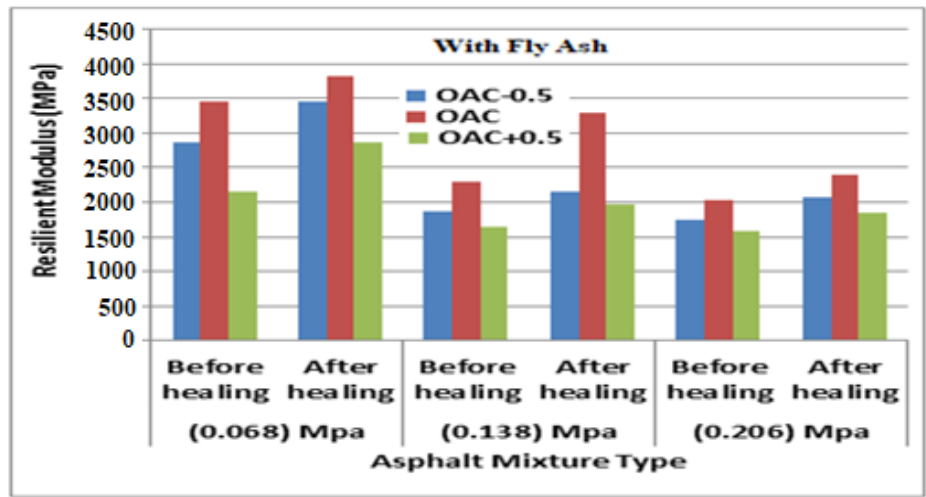

Figure 11. Influence of Healing on Mr For Mixes (With Fly Ash)

\section{Conclusions}

Based on the limitations of the testing program, the following conclusions may be drawn.

1) The Mr increases after inclusion of fly ash by (66, 50 and 31) \%, (36, 50 and 31) \% and (62, 37 and 69) \% for SMAC mixtures at (OAC-0.5, OAC and OAC+0.5) \% binder content under $(0.068,0.138$ and 0.206) MPa of repeated compressive stress respectively.

2) The permanent deformation decreases by $(25,11.4$ and 25$) \%,(19,31.6$ and 14.5$) \%$ and $(14,9$ and 8.3$) \%$ after implementation of fly ash at (OAC-0.5, OAC and OAC+0.5) \% binder content under $(0.068,0.138$ and 0.206$)$ $\mathrm{MPa}$ of repeated compressive stress respectively.

3) The resilient modulus increased by $(17.6,15.4$, and 10.5$) \%,(42.8,51.0$, and 37.5$) \%$ and $(18.7,2$, and 23.6) \% under three level of compressive stresses $(0.068,0.138,0.206) \mathrm{MPa}$ at $\left(25^{\circ} \mathrm{C}\right)$ after healing cycle for SMAC mixtures without fly ash and with $(4.6,5.1,5.6) \%$ asphalt content respectively. 
4) The resilient modulus increased by $(19.8,15.5$, and 17.7) $\%,(11.3,43.3$, and 18.8) $\%$ and $(33.4,19.5$, and $15.7) \%$ under three level of compressive stresses $(0.068,0.138,0.206) \mathrm{MPa}$ at $\left(25^{\circ} \mathrm{C}\right)$ after healing cycle for SMAC mixtures with fly ash and with $(4.6,5.1,5.6) \%$ asphalt content respectively.

5) The variation in slope value is not significant for different mixtures and different level of stresses. The impact of using fly ash on deformation can be detected by the reduction of permanent microstrain (intercept) by (69.6, $43.2,0.5) \%$ after inclusion of fly ash at optimum asphalt content under (0.068, 0.138 and 0.206) MPa stress level respectively.

\section{References}

[1] NAPA. Designing and Constructing SMA Mixtures-State of the Practice. Quality Improvement Series 122. National asphalt pavement association NAPA. 2002 www.asphaltpavement.org.

[2] Ghasemi M, Marandi SM. Laboratory investigation of the properties of stone matrix asphalt mixtures modified with rgp-sbs. Digest Journal of Nanomaterials and Biostructures. 2011;6(4):1823-1834.

[3] Cooley A, Brown E. Potential of using stone matrix asphalt (SMA) for thin overlays. National center for asphalt technology, NCAT. Report 03-01. 2003.

[4] Awanti SS. Laboratory Evaluation of SMA Mixes Prepared with SBS Modified and Neat Bitumen. ProcediaSocial and Behavioral Sciences. 2013;104:59-68.

[5] Babagoli R, Hasaninia M, Mohammad Namazi N. Laboratory evaluation of the effect of Gilsonite on the performance of stone matrix asphalt mixtures. Road Materials and Pavement Design. 2015;16(4):889-906.

[6] Mashaan NS, Ali AH, Koting S, Karim MR. Dynamic properties and fatigue life of stone mastic asphalt mixtures reinforced with waste tyre rubber. Advances in Materials Science and Engineering. 2013;2013.

[7] Chiu CT, Lu LC. A laboratory study on stone matrix asphalt using ground tire rubber. Construction and Building Materials. 2007;21(5):1027-1033.

[8] Sarang G, Lekha BM, Geethu JS, Shankar AR. Laboratory performance of stone matrix asphalt mixtures with two aggregate gradations. Journal of Modern Transportation. 2015;23(2):130-136.

[9] Sarsam SI, Khalil SM. Dynamic Behavior of Stone Matrix Asphalt Concrete (SMA). International Journal of Emerging Engineering Research and Technology. 2019; 7(2):1-8.

[10] ASTM. American Society for Testing and Materials, Road and Paving Material, Vehicle-Pavement System, Annual Book of ASTM Standards, 2013, Vol.04.03.

[11] SCRB. General Specification for Roads and Bridges, Section R/9 Hot-Mix Asphalt Concrete Pavement, Revised Edition, State Corporation of Roads and Bridges, Ministry of Housing and Construction, 2003, Republic of Iraq.

[12] Brown ER, Mallick RB, Haddock JE, Bukowski J. Performance of stone matrix asphalt (SMA) mixtures in the United States, NCAT Report No. 97-1, 1997, Auburn University, Alabama.

[13] Asi IM. Laboratory comparison study for the use of stone matrix asphalt in hot weather climates. Construction and Building Materials. 2006;20(10):982-989.

[14] Myers NM. Stone Matrix Asphalt, the Washington Experience. [MSc. Thesis]. University of Washington. June 2007.

[15] Nejad FM, Aflaki E, Mohammadi MA. Fatigue behavior of SMA and HMA mixtures. Construction and Building Materials. 2010;24(7):1158-1165.

[16] Bernard B. A Review on Various Issues Related to Stone Matrix Asphalt. Int. J. Pavement Res. Technol.. 2017;4(12):588-591.

[17] Sarsam SI, Jasim SA. Assessing the Impact of Polymer Additives on Deformation and Crack Healing of Asphalt Concrete Subjected to Repeated Compressive Stress. In: 17th Annual International Conference on Asphalt, Pavement Engineering and Infrastructure, 2018 LJMU, Liverpool, UK.

[18] Sarsam SI. Crack healing potential of asphalt concrete pavement. International Journal of Scientific Research in Knowledge. 2015;3(1):001-012.

[19] NAPA, National Asphalt Pavement Association. Guidelines for Materials, Production, and Placement of Stone Matrix Asphalt (SMA), Technical Working Group (TWG), Publication No. IS 118, 1994, Lanham, Maryland.

[20] Tashman L, Pearson B. Characterisation of stone matrix asphalt mixtures. International Journal of Pavement Engineering. 2012;13(4):297-309.

[21] Ahmadinia E, Zargar M, Karim MR, Abdelaziz M, Ahmadinia E. Performance evaluation of utilization of waste Polyethylene Terephthalate (PET) in stone mastic asphalt. Construction and Building Materials. 2012;36:984-989.

[22] Sarsam S. and Husain A. Influence of Nano materials on micro crack healing of asphalt stabilized subgrade soil. Applied Research Journal ARJ, Vol.1, Issue, 7, 2015, P.395-402, September. 
[23] Qiu YF, Lum KM. Design and performance of stone mastic asphalt. Journal of transportation engineering. 2006;132(12):956-963. 